\title{
INTRODUCTION OF ELEMENTS FROM PROBABILITY THEORY IN THE EDUCATION IN MATHEMATICS FOR PRIMARY SCHOOL
}

\section{Maria Temnikova ${ }^{1}$}

\begin{abstract}
The article considers the prerequisites for the inclusion of problems with elements of probability theory in mathematics education in grades 1-4. This type of task is generally not present in the compulsory curriculum in mathematics in primary school, but they could be used in classes for compulsory, extended, and additional training, thus creating conditions for implementing developmental learning.

Some theoretical statements about the theory of probabilities are systematized, related to the tasks included in the constructed and approbated methodological system of work. Some of its characteristics are presented. This article offers some of the tasks for grades 1-4.

A longitudinal empirical study was conducted with students of the 1-4th grade in the period 2015 to 2020 . The results of the outgoing diagnostics in 4th grade are processed by mathematical and statistical methods and are presented graphically. They show that fourth-graders successfully solve problems with elements of probability theory, and a primary school teacher could use them in the systematic work in mathematics at the initial stage of the basic educational degree.

Solving non-standard mathematical problems is an element of probability theory that helps arouse interest, motivate students, and place them in an active cognitive position by solving problem situations in the pedagogical interaction in mathematics in primary school.
\end{abstract}

UDC Classification: 37.01, DOI: https://doi.org/10.12955/pss.v2.241

Keywords: problems with elements of probability theory, training in mathematics

\section{Introduction}

Contemporary education in mathematics for Grades 1-4 in Bulgarian primary school is based on extraordinary rich traditions. The intention is to provide each student with basic mathematical knowledge as well as skills to select, systematize, use, understand information, and consequently apply it.

A combination of material from the area of arithmetic, geometry, and elements of algebra represents the main educational content.

Very often in life, one has to solve tasks and problems which happen to be related to the Probability Theory. For this reason, such tasks and problems are included in suitable form in the educational content. The issue with the inclusion of mathematical tasks from the area of probability in the Primary school educational program and the methodology for work with such tasks during mathematics classes has never been. Currently, it is not a priority in the popular specialized literature in Bulgaria.

Nowadays the educational process in mathematics in Primary school is carried out during classes for extended and additional study. During the classes for additional study, teachers can create such pedagogical conditions to put students in an active cognitive position and successfully solve mathematical tasks from a type different from those studied during compulsory classes. Seeking solutions in this direction must be agreed upon on three levels: content, didactically, and methodologically. The methodology work with mathematical tasks from the area of probability is the focal point of this research work.

The research aims to develop a methodology system of work with tasks that include elements from the probability theory and are based on this theory's theoretical concepts. This methodology system of work shall be used during mathematics classes for extended and additional education to identify the students' level of knowledge, skills, and competencies for work with such tasks.

The object of the research work is the process of education in mathematics during extended and additional classes in Primary school.

The subject of the study is the efficiency of the newly developed methodology system of work on the process of knowledge acquiring, forming of skills, and developing competencies in the students for solving mathematical tasks with incorporated elements from the Probability Theory.

The following methods are used in the research work: didactical experiment, content analysis, observation, tests, mathematics-statistics methods for processing the results.

\footnotetext{
${ }^{1}$ Trakia University, Faculty of Education, Stara Zagora, Bulgaria, mpt66@abv.bg
} 


\section{Literature review}

In the analyzed literature sources, including Balabanova and Dineva (1995), Kozhuharova (2013), Savin (1985) the main theoretical concepts related to Probability theory do not defer. One of the authors, Savin (1985) introduced a definition for probability: "The probability is a numerical characteristic for the possible occurrence of random events in certain conditions that can be reproduced an unlimited number of times" (Savin, 1985, p.37).

"The probability refers to "attempt" as to the accomplishment of a certain set of conditions. For example, throwing coins or dices, a quality test of an electric bulb randomly chosen from a bulk of electric bulbs, etc." (Milkov, 1996, p. 139). Balabanova and Dineva clarified the meaning of "attempt" and "outcome" giving several examples and the following summary: "Typically for each one of the presented attempts, only one of all possible outcomes comes true. All possible outcomes are known in advance. The attempt can be repeated an unrestricted number of times. All outcomes from the attempt have equal chances to come true" (Balabanova, Dineva, 1995, p. 269).

The event that will always come true after a particular attempt is called a certain event. For example, the following event A is a certain event: "Let us take out a white ball from a box that contains only white balls". An event that will never come true after a particular attempt is called an impossible event. An example of an impossible event is the following event B: "Let us take out a black ball from a box that contains only white balls."

After a particular attempt, an event that can either come true or not but never both simultaneously is called a random event. For example, a random event is the following event $\mathrm{C}$ : "Let us take out a white ball from a box that contains both white and black balls."

There are two standpoints regarding the age from which students can start studying probability tasks. Chapman (1975) and Piaget \& Inhelder (1975) support that students can start studying probability tasks from Grade 5 onwards. According to them, smaller Grade students would have difficulties solving probability tasks.

Opposite, Bryant \& Nunes (2012), Davies (1965), Goldberg (1966), Kennedy et al. (2008), Nilsson (2007, 2009), Polaki (2002) share the understanding that probability tasks can be studied still in the Primary school.

The MSKL program (a program for mathematical and scientific knowledge and learning) is a national program of the issues and development of mathematical and scientific knowledge and learning, which is being worked on in the USA. It consists of fundamental elaborations and those with a practical focus. One of the fields of competency dealt with in it is "conceptual knowledge in the sphere of probabilities" (Tonova, 2012, p. 26).

Countries like Australia, Canada, Finland, and USA have good practices and results achieved after including mathematical tasks from the area of probability in the education for Primary school.

Would the students at the initial stage of the basic educational degree still be able to solve also tasks with elements of probability theory, thus creating a good knowledge base, skills, and competencies on which it will be upgraded in the next degrees of study?

Considering the understanding of the supporters of the study of probability tasks in Grades 1-4 we offered some non-standard tasks with elements of probability theory in mathematics training through which it will contribute to increasing the cognitive level of students and development of their logical thinking.

\section{Methodology}

Below is a presentation of some of the specifics of the newly developed methodology system of work for solving tasks that incorporate elements of probability. This methodology system of work creates conditions for students to acquire knowledge for solving such types of tasks. The mathematical tasks included in the methodology system are the main tool for developing students' skills and facilitating the process of building the elements of the competencies needed for solving these tasks. Additionally, the tasks in question complement each other and create a complex repeating situation for developing education during mathematics classes in grades 1-4.

When working with tasks from the area of probability, teachers do not use specific terminology and symbols during mathematics classes in grades 1-4. 
Some of the algorithms included in the methodology system of work and used for solving probability tasks are explained below.

The events subjected to the tasks are random, equally possible, possible, complex, and incompatible. In order for one event to come true, a sufficient number of attempts must be performed. First, the "worst" case scenario must be considered, the "worst" probability of this particular event to come true.

The events can be labeled with block letters A, B, C, etc. All tests related to the events must be taken into consideration.

The text of any particular task will determine how many tests must be performed (taking out of pencils in the below task) to ensure that the searched event will come true.

Task: In a drawer, there are 2 yellow and 2 green pencils. Without looking in the drawer, how many pencils need to be taken out to ensure that at least one green pencil will be taken out?

In a course of a discussion, the teacher and the students consider the number of taking-outs that need to be performed to make sure that the probability to "take out at least one green pencil" is $100 \%$.

Event A - take out a yellow pencil. Event B - take out a green pencil.

These two events configure a complete system of events. They have an equal number of favorable and unfavorable cases -2 . To be sure $100 \%$ that we will take out at least one green pencil without looking into the drawer, we must consider the "worst-case" scenario, the "worst" probability, and the following tests: First taking-out - we take out a pencil of an undesirable color (yellow in this case). So we take out 1 yellow pencil. Second taking-out - here we also take out a pencil of the undesirable color or we take out 1 yellow pencil. We carry on until we take out all subjects (pencils in this case) with an undesirable color. Going back to the text of the concrete task, the total number of yellow pencils is 2 so all yellow pencils have already been taken out. Third taking-out - we surely take out a green pencil as all yellow pencils have already been taken. Therefore, 3 pencils need to be taken out to be $100 \%$ sure that at least one green pencil has been taken out.

The students need to understand that taking-outs must start from the objects with the color opposite to the color required in the text of the task. For example, the task: Anny has got 2 pink and 2 blue balloons. She took 3 of them. What might be the color of all three of them? The teacher may decide to use models of the balloons -2 pink and 2 blue circles. The students can have their models and work with them on their desks. Using the method of demonstration, the options of all possible takings can be shown. For example: Option of the first taking: 2 pinks and 1 blue balloon. Option for the second taking: 2 blue and 1 pink balloon.

The below tasks have been developed by Temnikova (Temnikova, 2018, pp. 181-183) and included in the new methodology system of work:

Task: Mimmy has got 2 red and 2 green balls. She took 3 of them. What might be their color?

Figure 1: Picture visualizing the task for grade 1

Task: In a dark room there are 3 white and 3 blue chairs. We take out 4 of them. What is the probability of having taken 2 chairs from each color?

\begin{tabular}{|l|l|l|}
\hline Figure 2: Picture visualizing the task for grade 1 \\
\hline Source: Temnikova (2018)
\end{tabular}


Task: There are 1 white and 2 purple balls in a bag. How many balls must we take out to be sure that one purple ball will be taken out?

\begin{tabular}{|l|}
\hline Figure 3: Picture visualizing the task for grade 1 \\
\hline Source: Temnikova (2018)
\end{tabular}

Task: There are markers with different colors in a box: 4 green and 4 blue markers. How many markers must Yavor take out to be sure that there will be 2 blue markers taken out?

\begin{tabular}{|l|}
\hline Figure 4: Picture visualizing the task for grade 1 \\
\hline Source: Temnikova (2018)
\end{tabular}

The methodology system of work includes tasks for grade 2 as well (Temnikova, 2018, pp. 184-185):

Task: In a box there are 4 black and 4 white toy cars. How many toy cars must be taken out of the box to be sure that at least one white toy car has been taken out?

Task: In a dark cartoon box there are 4 blue student boxes and 4 grey student boxes. How many student boxes must be taken out to be sure that there are at least 2 student boxes with different colors taken out?

Task: In a box, there are 5 white and 5 black buttons. We have taken 6 of them out. Are there at least 3 buttons with the same color amongst them?

Below are some of the tasks for grades 3 and 4, which contain elements from the Probability theory and that have been included in the methodology system of work:

Task: In a dark room there are 6 white and 6 red balls. How many balls must one take out to be sure that at least 1 red ball has been taken out?

Task: There are 7 red and 7 yellow apples in a bag. How many apples must be taken out of the bag to have at least 2 yellow apples taken out?

Task: At a children's party there were pieces of cake of different colors: 4 chocolate brown, 3 white, 2 red and 1 yellow. A child has been told to take several pieces of cake but to make sure that he will take at least 2 pieces from each color. How many pieces has this child taken?

Task: Svante "the little brother" has got 15 jars of confiture of the same size: 7 jars with strawberry confiture, 6 jars with raspberry confiture and 3 jars with Morello cherry confiture. How many jars can Carlson "take" and make sure that Svante will still have 4 jars of marmalade from one type, and 3 jars of marmalade from another type left?

\section{Results}

Over the period between 2015 and 2017, research work has been carried out in Petko Rachov Slaveykov Primary school, the town of Stara Zagora, Bulgaria. The purpose of the research work was to study the students' level of knowledge and skills from grades 1-4 to solve mathematical tasks that include elements from the Probability Theory during the extended and the additional mathematics classes. Two classes of students with statistically equal levels of educational achievements have been subjected to the study. One of the classes was the experimental class, where the newly developed methodology system of work has been applied. The other class was the referent one where the new methodology system of work has not been applied. 
The empiric research work used two tests. The first test was to determine the entry diagnostic of the students' knowledge and skills to solve mathematical tasks with elements from the Probability theory. The purpose of the second test was to determine the exit diagnostic of the same skills and knowledge.

The researchers studied the objectivity, validity, and reliability of the tests as well as the level of difficulty and the separating force of tasks included in these tests.

The entry diagnostic results showed no statistically important difference between the relative shares of the students from the experimental and the referent class subjected to the study in respect of their level of knowledge and skills. After completing the experimental work, the exit diagnostic showed that there is a significant difference between the results achieved by the students from the experimental and the referent class.

The students' level of knowledge and skills from the experimental class who correctly solved mathematical tasks with elements from the area of the probability increased from 54,6\% up to $92,4 \%$. The percentage of the students from the experimental class who made mistakes dropped down to $5,8 \%$, while the percentage of the same students from the referent class was $31,3 \%$. This difference was proved to be statistically significant.

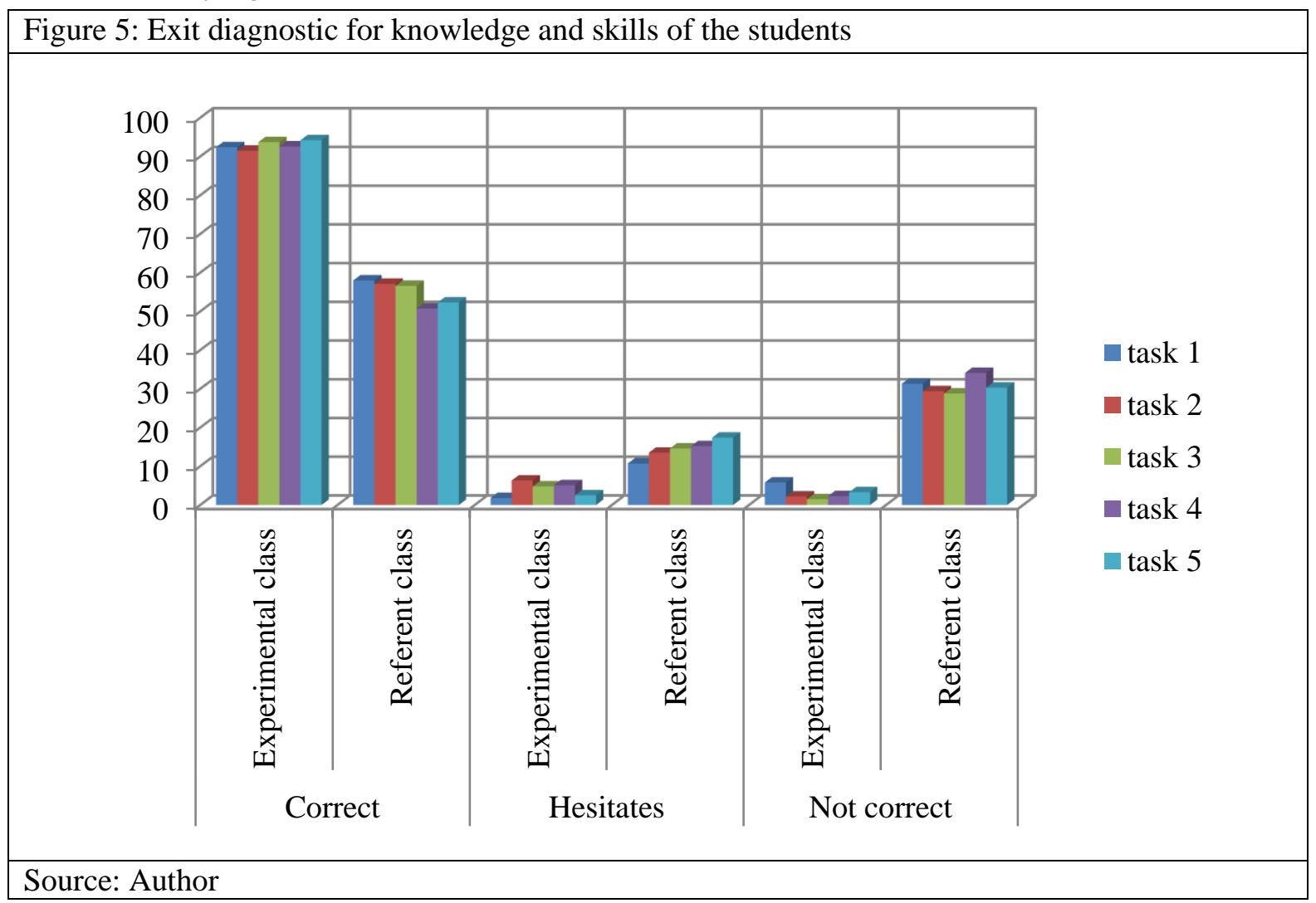

\section{Conclusions}

Results of the research work demonstrated that the grade 1-4 students successfully solved tasks from the area of probability. This means that such tasks can be included in the educational content of the classes for extended and additional education in mathematics in Primary school.

The presence of systematized elements from the Probability theory will help promote the unified nature of the education in mathematics, expand and deepen students' knowledge in mathematics in grades 14 , and raise the level of education in mathematics in Primary school. Such tasks can facilitate the development of the mathematical worldview of the young students, develop their logical thinking, observe and improve their attention, and form such qualities of the child thinking as broadness and flexibility.

Solving such tasks students acquire knowledge and skills that become the basis for studying probabilities in the next stages of their education. All this creates a work environment where students are encouraged to do research work, transverse knowledge, skills, competences, and competencies, and seek different ways to solve tasks. 


\section{References}

Balabanova, R., E. Dineva, (1995). Matematika [Mathematics]. Burgas, 269.

Bryant, P., T. Nunes, (2012). Children's understanding of probability: A literature review (full report). The University of Oxford. Nuffield Foundation.

Chapman, R. (1975). The development of children's understanding of proportions. Child Development, 46 (1).

Davies, C. M. (1965). Development of the probability concept in children. Child Development, 36 (3).

Goldberg, S. (1966). Probability judgements by preschool children: Task conditions and performance. Child Development, 37 (1).

Kennedy, M. L., S. Tipps, A. Johnson, (2008). Investigating Probability. Guiding Children's Learning of Mathematics, Eleventh Edition, Thomson Wadsworth, USA.

Kozhuharova, G. (2013). Kombinatorika, teoria na veroyatnostite I statistika [Combinatorics, probability theory and statistics], Acad. Ed. of Trakia University, Stara Zagora.

Milkov, D. (1996). Informacionni matematicheski metodi v pedagogikata [Informatics and mathematical methods in pedagogy]. Univ. Ed. of “St. Climent Okhridski” University, Sofia, 139.

Piaget, J., B. Inhelder, (1951/1975). The Origins of the Idea of Chance in Children, New York: Norton.

Polaki, M. V. (2002). Using instruction to identify key features of basotho elementary students' growth in probabilistic thinking. Mathematical Thinking and Learning, 4 (4).

Savin, A. G. (1985). Encyclopedic dictionary of young mathematicians for middle and senior school age. Moscow, 37.

Temnikova, M., (2018). Zadachi ot kombinatorikata I teoriya na veroyatnostite v obuchenieto po matematika v 1-4. klas [Problems from combinatorics and probability theory in mathematics training in the 1st-4th grade], Stara Zagora, 181-185.

Tonova, T. (2012). Kognitivni modeli v matematicheskoto obuchenie na uchenici ot 3 do 6 klas [Cognitive models in mathematics training for students of the 3rd - 6th grade, dissertation work], Sofia, 26. 